\title{
A NOTE ON $k$-PARANORMAL OPERATORS
}

\author{
C. S. Kubrusly and B. P. Duggal
}

Abstract. It is still unknown whether the inverse of an invertible $k$-paranormal operator is normaloid, and so whether a $k$-paranormal operator is totally hereditarily normaloid. We provide sufficient conditions for the inverse of an invertible $k$-paranormal operator to be $k$-paranormal.

Mathematics subject classification (2010): Primary 47A45, Secondary 47B20.

Keywords and phrases: $k$-paranormal operators, normaloid operators.

\section{REFERENCES}

[1] H.K. CHA, K.I. SHIN AND J.K. KIM, On the superclasses of quasihyponormal operators, J. Korea Soc. Math. Educ., 7 (2000), 79-86.

[2] R.G. Douglas, Canonical models, Topics in Operator Theory (Mathematical Surveys No.13, Amer. Math. Soc., Providence, 2nd pr. 1979), 161-218.

[3] B.P. Duggal, On dominant operators, Arch. Math. (Basel), 46 (1986), 353-359.

[4] B.P. DugGal, On characterising contractions with $C_{10}$ pure part, Integral Equations Operator Theory, 27 (1997), 314-323.

[5] B.P. DugGal AND S.V. DJoRdJEVIĆ, Generalized Weyl's theorem for a class of operators satisfying a norm condition, Math. Proc. Royal Irish Acad., 104 (2004), 75-81.

[6] B.P. Duggal, S.V. DJordjević And C.S. Kubrusly, Hereditarily normaloid contractions, Acta Sci. Math. (Szeged), 71 (2005), 337-352.

[7] B.P. Duggal And C.S. KubRusLY, Paranormal contractions have property PF, Far East J. Math. Sci., 14 (2004), 237-249.

[8] T. FurUtA, Invitation to Linear Operators, Taylor and Francis, London, 2001.

[9] T. Furuta, M. ITO AND T. YAMAZAKI, A subclass of paranormal operators including class of log-hyponormal and several related classes, Sci. Math., 1 (1998), 389403.

[10] V.I. IstRĂŢESCU, Introduction to Linear Operator Theory, Marcel Dekker, New York, 1981.

[11] M. ITO AND T. YAmAZAKI, Relations between two inequalities $\left(B^{\frac{r}{2}} A^{p} B^{\frac{r}{2}}\right)^{\frac{r}{p+r}} \geqslant B^{r}$ and $A^{p} \geqslant$ $\left(A^{\frac{p}{2}} B^{r} A^{\frac{p}{2}}\right)^{\frac{p}{p+r}}$ and their applications, Integr. Equ. Operator Theory, 44 (2002), 442-450.

[12] P.R. Halmos, Normal dilations and extensions of operators, Summa Brasil. Math., 2 (1950). 125134.

[13] C.S. Kubrusly, An Introduction to Models and Decompositions in Operator Theory, Birkhäuser, Boston, 1997.

[14] C.S. KubRusly, Hilbert Space Operators, Birkhäuser, Boston, 2003.

[15] C.S. Kubrusly And B.P. Duggal, On posinormal operators, Adv. Math. Sci. Appl., 17 (2007), 131-147.

[16] C.S. KubRusly And P.C.M. VieIRA, Strong stability for cohyponormal operators, J. Operator Theory, 31 (1994), 123-127.

[17] K. ОкUво, The unitary part of paranormal operators, Hokkaido Math. J., 6 (1977), 273-275.

[18] C.R. Putnam, Hyponormal contractions and strong power convergence, Pacific J. Math., 57 (1975), 531-538.

[19] H.C. Rhaly, JR., Posinormal operators, J. Math. Soc. Japan, 46 (1994), 587-605.

[20] A.L. SHIELDS, Weighted shifts operators and analytic function theory, Topics in Operator Theory (Mathematical Surveys No.13, Amer. Math. Soc., Providence, 2nd pr. 1979), 49-128b. 
[21] J.G. StAmpfli And B.L. WAdHWA, An asymmetric Putnam-Fuglede theorem for dominant operators, Indiana Univ. Math. J., 25 (1976), 359-365.

[22] J.G. Stampfli and B.L. Wadhwa, On dominant operators, Monatsh. Math., 84 (1977), 143-152.

[23] B. Sz.-NAGY AND C. FoIAŞ, Harmonic Analysis of Operators on Hilbert Space, North-Holland, Amsterdam, 1970.

[24] T. Yoshino, On the unitary part of dominant contractions, Proc. Japan Acad. Ser. A Math. Sci., 66 (1990), 272-273.

[25] T. Yoshino, Introduction to Operator Theory, Longman, Harlow, 1993. 